\title{
Ferramenta para Análise e Gestão de Custos da Atividade Cafeeira em Pequenas e Médias Propriedades Rurais
}

\author{
Tool for Analysis and Cost Management of Coffee Activity in Small and Medium Rural \\ Properties
}

\author{
Luiz Felipe Sacardo*a; Michele Ribeiro Ramos ${ }^{\mathrm{a}}$ \\ ${ }^{a}$ Centro Regional Universitário Espírito Santo do Pinhal. SP, Brasil. \\ *E-mail: adm.felipesacardo@gmail.com
}

\begin{abstract}
Resumo
O Agronegócio é responsável por cerca de 1/4 das riquezas geradas anualmente no Brasil. Dentro deste universo a cultura cafeeira é responsável por cerca de $10 \%$ do volume total das exportações deste setor. A viabilidade da produção cafeeira em qualquer escala depende fortemente da agregação de qualidade no produto final, eficiência nos processos e o controle dos custos da atividade. Os pequenos e médios cafeicultores, de maneira geral, ainda carecem de uma estrutura administrativa que lhes permita conhecer e gerencia adequadamente suas finanças, apesar de existir uma consciência da necessidade do conhecimento e gerenciamento dos custos de produção o que ainda vemos são as finanças das atividades sendo misturadas com as finanças pessoais, impossibilitando qualquer tipo de análise precisa e ainda, uma forte tendência de subjugar os custos e despesas e de inflacionar os resultados finais, mesmo que estes não estejam explícitos. Fatores como má administração do fluxo de caixa ou até mesmo menosprezo por pequenas despesas no cálculo do resultado podem ser o diferencial entre aqueles produtores que prosperam e aqueles que têm de deixar a atividade.
\end{abstract}

Palavras-chave: Microanálise de Empresas Agrícolas. Modelos Econométricos e de Entrada-Saída. Investimento.

\begin{abstract}
Agribusiness is responsible for about $1 / 4$ of the wealth generated annually in Brazil. Within this universe, coffee culture is responsible for about $10 \%$ of the total export volume of this sector. The viability of coffee production on any scale strongly depends on the aggregation of quality in the final product, process efficiency and cost control of the activity. With the administrative modernization of the activity efficiency is gained, and with the efficiency gain opportunities for greater financial gain arise, either through cost reduction or revenue increase. Small and medium coffee farmers, in general, still lack an administrative structure that allows them to know and manage their finances properly, although there is an awareness of the need for knowledge and management of production costs. What we still see is the finances of the activity mixed with personal finances, precluding any kind of precise analysis and yet a strong tendency to subjugate costs and expenses and to inflate final results, even if they are not explicit. Factors such as poor cash flow management or even contempt for small expenses in calculating income may be the difference between those who thrive and those who have to leave the business.
\end{abstract}

Keywords: Micro Analysis of Farm Firms. Econometric and Input-Output Models. Investment.

\section{Introdução}

Responsável por $10 \%$ das exportações do agronegócio, grande geração de riqueza e de empregos cada vez mais especializados a cultura cafeeira teve papel primordial no desenvolvimento do agronegócio brasileiro no século passado, sendo por muitos anos o principal "commoditie" nacional. Ainda com importante papel no cenário agropecuário nacional, evidencia-se para os produtores cafeeiros no século XXI o desafio de se tornarem mais eficientes a cada safra, e a eficiência passa primordialmente por gestão de custos. (CEPEA, 2018). Assim, surge a necessidade de uma ferramenta para gestão financeira com enfoque na eficiência e nos custos de produção.

A ferramenta elaborada para análise de custos de produção agropecuária consiste em uma planilha eletrônica, visualizável e editável no "software" Microsoft Excel com o intuito de auxiliar pequenos e médios produtores de café a registrar, mensurar, analisar e controlar seus custos de produção.
Considerando que a gestão é caracterizada pelo conjunto de atividades administrativas e operacionais (de produção) que são direcionadas para a utilização eficiente e eficaz dos meios produtivos, objetivando alcançar metas estabelecidas no plano de negócios do empreendimento, fazer gestão passa primordialmente por conhecer aquilo que se está ou que se pretende gerir, e só é possível conhecer a partir do momento que se mensura (SILVA, 2005).

É de comum conhecimento da comunidade acadêmica e do setor agropecuário a deficiência que o público-alvo desta ferramenta possui em relação ao conhecimento detalhado e na gestão de seus custos de produção, como observado em outros setores da economia, o setor agropecuário também apresenta características ímpares o que demanda soluções diferenciadas. A gestão de custos é uma importante área de estudo que permite ao produtor rural aperfeiçoar o gerenciamento das atividades, e consequentemente elevar padrões de qualidade, eficiência e lucratividade (SENAR, 2015). 
Crepaldi (2012) cita de forma sintetizada cinco objetivos do produtor rural, um dos mais importantes se caracteriza na necessidade de aumentar a lucratividade por pelo menos um dos dois meios: Aumento do nível da produção/qualidade ou controle dos custos produtivos. Desta maneira, considerando que a cultura cafeeira gera uma "commoditie", ou seja, produtos primários, onde dificilmente é possível agregar valor sem beneficiamento, diferenciação por qualidade ou industrialização, e considerando os altos custos logísticos observados em nosso país, a margem de ganho na venda de seus produtos depende fortemente de um sólido controle de custos, tal como gestão da eficiência em todos os processos.

Sabendo disso, é fundamental que os produtores rurais tenham o domínio de seus custos e se mantenham competitivos, principalmente os pequenos e médios, que devem não somente conhecer, mas gerenciar seus custos de forma a atingir níveis cada vez maiores de excelência, uma vez que não conseguem competir em escala com os grandes produtores e se veem cada vez mais pressionados devido às inovações tecnológicas e novas técnicas que são, geralmente, adotadas primeiro pelos grandes agropecuaristas. Contudo, a questão chave é: Como gerenciar se não é mensurado de maneira profissionalizada?

A partir deste questionamento surge a importância desta ferramenta, que tem a função de auxiliar os produtores rurais, pequenos e médios, no processo de inserção, análise e gestão de seus custos de produção com a finalidade de se tornarem mais competitivos e eficientes.

Uma ferramenta simples, intuitiva e de fácil utilização e compreensão, que irá receber dados de entrada, informados pelo usuário a respeito de áreas, dimensões, produtividade, gastos com insumos, gastos com manutenção da terra, gastos com o plantio, gastos com manejo, gastos com colheita e demais e irá apresentar informações compiladas, separadas por grupos específicos e tópicos de interesse, com gráficos que irão auxiliar na visualização eficiente destas informações.

Focado na cultura cafeeira, a ferramenta propõe uma imersão nos números da atividade, de tal maneira que deverá ser possível um aprofundamento muito maior nos fatores primordiais de custos e despesas associados à produção, com exceção apenas dos custos de formação dos cafezais. A ferramenta permite, portanto, processar os dados informados, apresentando informações detalhadas dos custos e despesas que deveram servir de referência para que os usuários consigam mensurá-los de forma geral ou específica, por fase de produção, por tipo de gasto, por aplicação específica, e assim, formar uma base história para análise e comparação entre períodos com o intuito de tornar a sua atividade mais eficiente e rentável.

\section{Material e Métodos}

Inicialmente foi aplicada uma pesquisa quantitativa onde foram obtidas 44 repostas, sendo 15 de produtores de café.
Do total dos entrevistados, 35 eram da região sudeste e 9 da região centro-oeste. A pesquisa foi realizada via Google Docs e durante 13 dias obteve respostas de produtores rurais de diversos portes e diversas culturas, dentre elas: Gado de corte, gado de leite, búfalas de leite, soja, milho, café, hortifrúti dentre outros.

Ela foi composta por 12 questões totais, sendo, 11 de escolha única e 1 de múltipla escolha. Das 12 questões, 10 eram de preenchimento obrigatório, de tal maneira que questões como sexo e idade não eram obrigatórias. Em nenhum momento foi possível evidenciar qualquer ligação ou qualquer nível de exposição aos pesquisados, uma vez que a pesquisa foi online, não exigiu identificação e as questões tratava-se em sua maioria de conceitos genéricos, nunca ligados especificamente a fatores que pudessem de alguma forma expor ou identificar informações ou a identidade dos pesquisados.

O tema principal da pesquisa foi: Custos e eficiência no Agronegócio, onde contou com a participação voluntária e totalmente consentida de produtores rurais de diversas regiões do país. O propósito da pesquisa com os produtores foi de mensurar e compreender quais fatores são fundamentais para a propriedade ter eficiência e cumprir o objetivo de provar que existe a consciência da importância da gestão de custos por parte dos produtores.

O questionário foi a base para a segunda etapa do trabalho que consistiu em elaborar uma ferramenta para análise, mensuração e gestão de custos para produtores de café. Apesar da pesquisa ter tido participação de produtores de diversas culturas, foi escolhida apenas uma, a atividade cafeeira para o enfoque da ferramenta, haja vista a complexidade da elaboração de uma ferramenta que atendesse de forma eficiente todas as culturas envolvidas.

Para a elaboração da ferramenta foi utilizado o "software" Microsoft Excel, o qual possibilitou o "input" de dados de todas as etapas da produção cafeeira, que seriam, por exemplo, gastos de tratos culturais, gastos de colheita, gastos de entressafra.

Ela contou com módulos de cadastro de propriedades, produtividade e produção bruta, módulo de cadastro de comercialização, módulo de cadastro de custos e despesas e módulo de geração de relatórios. Dentro de relatórios foi possível visualizar de forma simples e prática os custos e despesas ordenados por diversas óticas, como: Custos por grupos de similaridade, custos por mês de inocorrência, análise detalhada de comercialização, armazenagem, beneficiamento além de módulo para análise financeira que inclui relatórios financeiros e fluxo de caixa dentre outros.

Este trabalho possuiu caráter prático onde a ferramenta proporcionou uma plataforma simples, porém eficiente, para "input" de dados e geração de informações que contiveram grau de detalhe necessário gerando-se histórico para comparação com a finalidade de prover informações para 
que o produtor pudesse se tornar mais eficiente em sua gestão de custos e auxiliá-lo nas tomadas de decisões objetivando melhor qualidade e maior lucratividade na produção de cafeeira.

\section{Resultados e Discussão}

\subsection{Dados obtidos com a pesquisa}

Nesta primeira etapa onde foi aplicada a pesquisa, de forma genérica para produtores rurais de diversas regiões do país e de diversas culturas, a finalidade de cumprir o objetivo de provar a deficiência na gestão de custos e gestão financeira na maioria das propriedades rurais do país foi cumprida, conforme seguirão os dados.

Da pesquisa, foi possível extrair algumas informações importantes, como por exemplo, o fato de $86,36 \%$ das respostas partirem de pessoas do sexo masculino e apenas $13,64 \%$ por pessoas do sexo feminino. Apesar de recente crescimento do número de mulheres no comando dos empreendimentos rurais, onde dados do CEPEA indicam que entre os anos de 2004 a 2015 este número tenha aumentado em 8,3\% impulsionado principalmente por mulheres com idade acima de 30 anos, casadas e com ensino médio e superior ainda existe um longo caminho a ser trilhado no que tange uma efetiva participação do gênero feminino na administração dos agronegócios (CEPEA, 2019).

Mais de $86 \%$ dos entrevistados declararam possuir 36 anos ou mais, enquanto apenas um participante, ou seja, 2,27\% se declarou com menos de 25 anos, o que evidencia que a maioria dos gestores entrevistados, como ocorre de forma geral no agronegócio brasileiro, são pessoas já formadas, com experiência, onde muitas vezes já assumiram as atividades ou estão em processo de sucessão familiar. Quanto a atividade que exerciam, mais de 50\% responderam que atuam na área agrícola e 47\% aproximadamente na atividade pecuária (Figura 1).

Figura 1 - Idade dos participantes

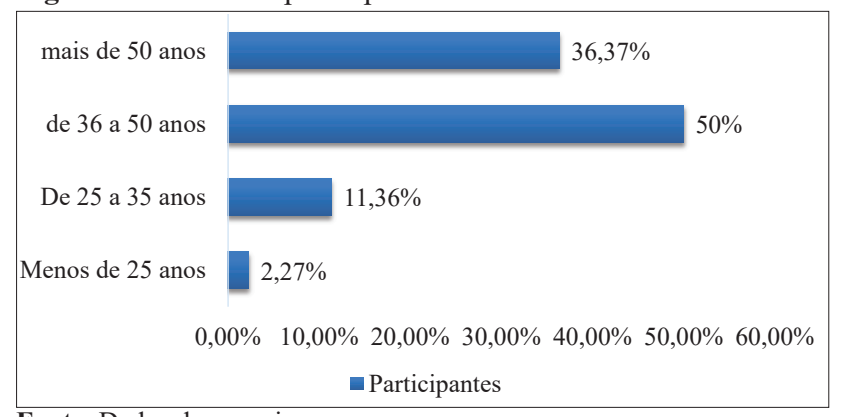

Fonte: Dados da pesquisa

É possível notar o grande equilíbrio entre a principal fonte de receita dos entrevistados, onde apesar da maior parte das receitas da agropecuária brasileira ser proveniente da agricultura, (BRASIL, 2018) notou-se que os pecuaristas se mostraram tão interessados ou até mais interessados no tema do que os agricultores considerando sua menor participação no PIB, porém participação praticamente similar na pesquisa.
Neste item da pesquisa, surpreende o fato de cerca de $45 \%$ dos entrevistados terem avaliado seu conhecimento relativo aos custos com nota 7 ou menor, especialmente quando cruzamos esta informação com as respostas da questão seguinte (Figura 2) onde é questionado em uma escala de 0 a 10 , onde zero representa a pior e 10 a melhor nota, qual a importância que os mesmos acreditam que o conhecimento detalhados dos custos de produção tem nas atividades rurais, $90 \%$ responderam com nota 10 , ou seja, importância máxima.

Figura 2 - Importância do conhecimento dos custos de produções dos entrevistados em uma escala de 0 a 10

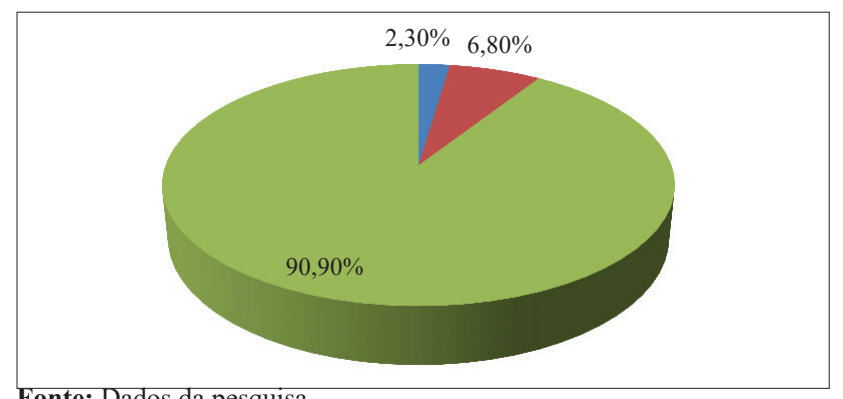

Fonte: Dados da pesquisa

Nota-se que aproximadamente $10 \%$ dos participantes não tem conhecimento dos custos de produção. Relativamente quando comparamos aos produtores que declararam possuir algum tipo de conhecimento sobre os custos de produção, percebe-se que a diferença é discreta, indicando que parte deles se preocupam com a gestão da atividade que desenvolvem.

Em se tratando de fornecer informações visando ganho de eficiência, a contabilidade e gestão de custos no agronegócio brasileiro pode ser considerada subdesenvolvida, a falta de conhecimento atrelado a uma mentalidade conservadora onde se prefere manter um controle baseado apenas em experiência, mas sem nenhum fundamento lógico ou mensuração precisa são os maiores motivos do não uso destas ferramentas de auxílio. Geralmente os produtores rurais ignoram ou não conhecem a importância das informações obtidas de forma transparente onde seria possível aplicá-las nas tomadas de decisão do dia a dia com eficiência muito maior (CREPALDI, 2009).

Ainda de acordo com Crepaldi (2009), a contabilidade rural vem constantemente sendo deixada de lado, onde uma grande maioria dos empresários rurais não conseguem nem ao menos separar o caixa pessoal, do caixa da atividade, fato que dificulta o correto gerenciamento dos resultados da atividade uma vez que se misturam com seus gastos e ganhos pessoais.

Neste sentido, 79,5\% dos entrevistados responderam com nota máxima a importância do conhecimento e gerenciamento dos custos para o ganho de eficiência e competitividade (Figura 3). Se expandirmos um pouco as respostas, considerando as notas 9 e 10 como sendo as duas de maior importância neste quesito, o número fica ainda maior, mais de $95 \%$. 
Figura 3 - Ganho de eficiência ao se conhecer detalhadamente os custos de produções dos entrevistados em uma escala de 0 a 10.

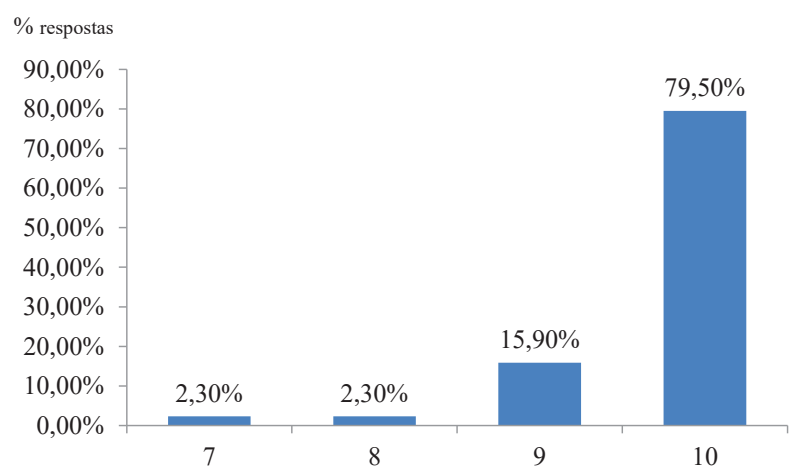

Fonte: Dados da pesquisa

Observa-se um grande equilíbrio quando o assunto é, qual o item que mais influência na variação do seu custo de produção (Figura 4). Fatores como custos financeiros, variação da moeda estrangeira, surgimento de novas pragas ou doenças e outros estão muito próximas sendo votadas como os fatores com maior peso na variação positiva dos custos, assim, não podemos apontar um único item responsável pela elevação dos custos quando estamos falando de controle deles, o que somente evidencia ainda mais a real necessidade de se fazer gestão financeira dentro da porteira.

Figura 4 - Fatores que mais impactam na variação dos custos de produção (em quantidade de respostas)

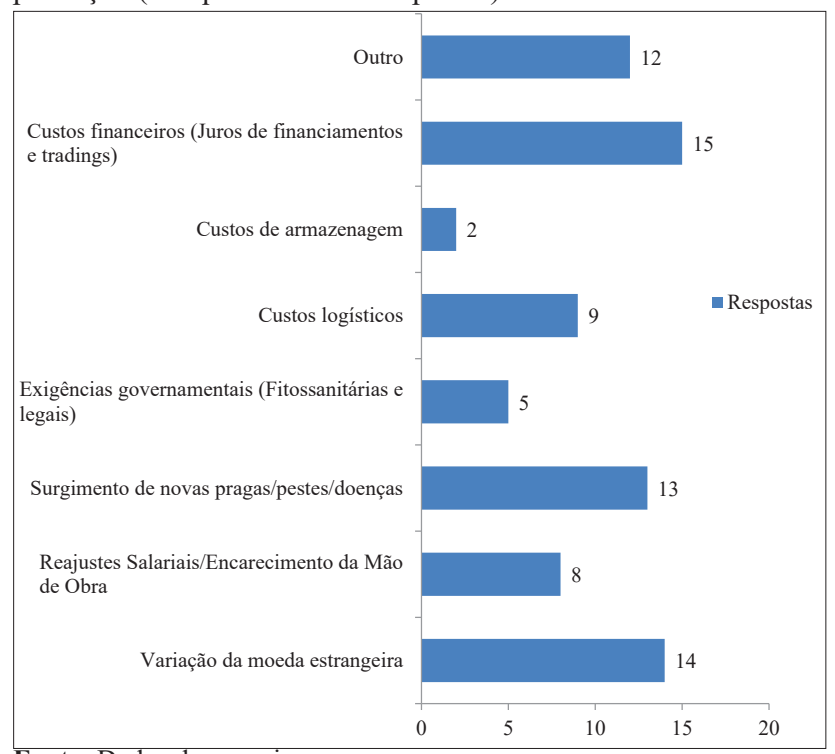

Fonte: Dados da pesquisa

Apesar de 95\% dos entrevistados julgarem com conceitos 9 e 10 o grau de importância da gestão de custos para o ganho de eficiência e competitividade, apenas 22,7\% declaram utilizar algum "software" para tal gestão. Para Santos, Marion e Segatti (2009), as mudanças ocorridas no setor agropecuário neste século levaram o produtor rural à necessidade de enxergar além do simples fato de produzir. Não basta mais apenas plantar e colher, é preciso também investir tempo na gestão.

Fatores como a alta competitividade global, mudanças nos aspectos trabalhistas e de mão de obra qualificada, questões políticas, ambientais e tributárias tornaram a linha entre a realização de lucro ou prejuízo mais estreita do que nunca; não dependendo mais apenas dos níveis de produtividade, mas de fatores externos a produção e principalmente a adequada gestão financeira.

Segundo Batalha (2009) existe uma grande variedade de "softwares" de gestão financeira rural disponíveis "online" para compra e alguns até mesmo disponibilizados de forma gratuita de maneira que todos os produtores, desde os pequenos até os maiores possuem condições de obter um destes "softwares" e utilizá-los na sua gestão financeira diária.

A pesquisa mostra ainda que mais de 56\% dos entrevistados estariam dispostos e elevar seus custos desde que conseguissem, pelo menos, o mesmo nível de ganho de produtividade e qualidade (Figura 5).

Figura 5 - Relação de importância entre qualidade e custos na visão dos entrevistados, dentre as opções disponíveis

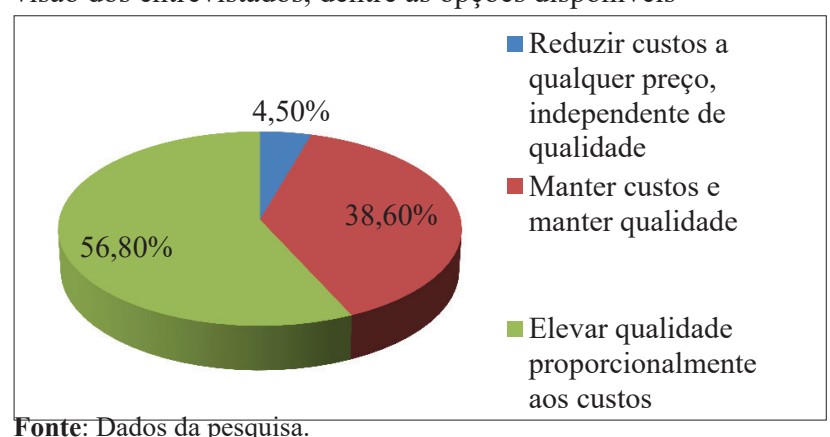

Fonte: Dados da pesquisa.

E ainda, 93\% estariam dispostos a disponibilizar tempo semanal para que um de seus colaboradores atuasse na mensuração e gestão de custos (Figura 6), no qual 13,60\% dedicariam o tempo de até 1 hora semanal e $34,10 \%$ concordam em que os colaboradores dedicassem de 3 a 5 horas para gestão de custos.

Figura 6 - Tempo disponível destinado a gestão e controle de custos de produção.

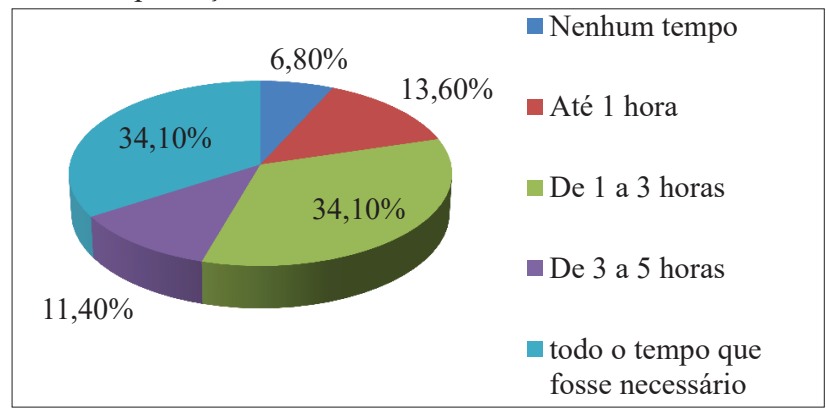

Fonte: Dados da pesquisa.

Analisando os 93\% que tem aceitam disponibilizar algum tempo semanal para os colaboradores atuar na gestão também estariam dispostos a realizar reuniões mensais com os colaboradores a fim de ouvir e compartilhar informações e práticas que pudessem levar ao ganho de eficiência financeira e reuniões sobre gestão de custos e eficiência com 
compartilhamento de informações estratégicas (Figura 7 e 8).

Figura 7 - Reuniões sobre gestão de custos e eficiência com compartilhamento de informações estratégicas

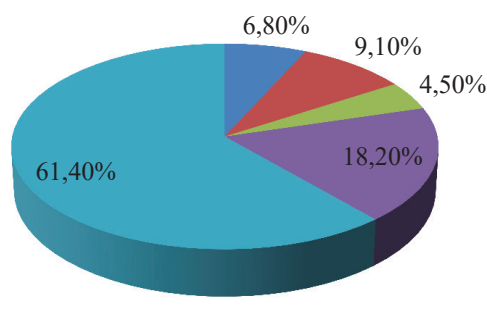

- Não acho importante este tema / não estaria disposto a dividir este tipo de informação

- Sim, mas apenas com o pessoal administrativo

- Sim, mas apenas com o pessoal operacional

- Sim, com todos os colaboradores

Fonte: Dados da pesquisa.

Moreno, 2013, revela que existem pontos de dificuldade entre os gestores em administrar o próprio tempo, considera ainda que é preciso utilizar métodos e estratégias para evitar o desperdício de tempo e aplicá-lo de forma eficiente para promover o sucesso da empresa.

A importância de se fazer reuniões é ressaltada por Ramos e Helal (2010), que ressalta que é o troca de conhecimento, resoluções de problemas organizacionais; além de serem informativas, e possibilitar troca de conhecimento. Joia e Oliveira (2007) ressaltam que as reuniões de trabalho estão entre as mais importantes ferramentas de geração e troca de conhecimento

Figura 8 - Disponibilidade de realização de reuniões mensais.

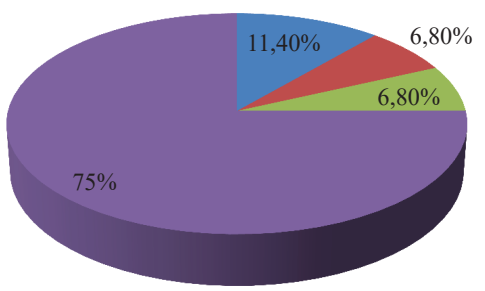

- Não acho importante este tema / não estaria disposto a dividir este tipo de informação

- Sim, mas apenas com o pessoal administrativo

- Sim, mas apenas com o pessoal operacional

Fonte: Dados da pesquisa.

Isto demonstra que entre a maioria dos entrevistados existe a consciência pela elevação dos padrões de eficiência, gestão e qualidade o que ainda falta é a iniciativa de colocar tudo isto em prática.

Dedicar tempo para organizar as informações, gerenciar custos e receitas é algo que os entrevistados, de acordo com a pesquisa, já entenderam que é de fundamental importância para o sucesso da produção. Uma empresa rural competitiva deve-se atentar a esses processos, considerando que controlar custos muitas vezes é a única opção para se ter aumento nas receitas.
É importante salientar que o sucesso da empresa rural depende diretamente de uma administração eficiente, e para se alcançar isso faz-se necessário conhecer o a atividade que está sendo desenvolvida, obter habilidades especificas para promover a modernização do negócio. Contudo infelizmente, esse o setor em que apresenta o maior nível de carência, como por exemplo falta de informação e entre outros (BORILLI et al., 2005).

Empresas rurais, de pequeno e médio porte, são, em sua grande maioria administradas por familiares, onde o administrador é o membro da família, sendo assim, muitas vezes as atividades desenvolvidas na fazenda fazem parte da rotina, do dia a dia do dele. Essa característica tem sido apontada como um fator de dificulta adesão de ferramentas de gestão. O compartilhamento de informações muitas das vezes se dá nos momentos familiares íntimos, causando algum tipo de prejuízo no processo de gestão.

Outra grande dificuldade encontrada é o pouco conhecimento das ferramentas contábeis que contribuem para o controle eficiente das atividades

De acordo com Domenico et al. (2015) a gestão é difícil de ser realizada, e os fatores que mais afetam negativamente estão relacionados ao desconhecimento do proprietário rural sobre os aspectos informacionais e de controle contábil, além da falta de recursos que facilitem as movimentações econômico e financeiras da propriedade.

\subsection{Resultados do uso prático da ferramenta}

Foi aplicada a utilização da ferramenta nas propriedades do cafeicultor A.G.S e seu pai A.S, localizadas no interior de São Paulo, e por motivos estratégicos optaram pela não divulgação de seus nomes.

Neste teste foi pedido que inicialmente eles informassem sem consulta a nenhum material ou anotações, os números sobre os custos e despesas de suas propriedades. Posteriormente, foi disponibilizada a ferramenta onde eles deveriam preencher de forma completa, agora sim utilizando todas as anotações, relatórios, notas fiscais e o que fosse necessário para que apurassem os custos de maneira mais real e detalhada possível, inclusive com consultas ao seu contador. Após o preenchimento, obtivemos os seguintes resultados:

Foi pedido que informassem com base em suas experiências e conhecimentos informações sobre o custo total anual, custo total com colheita, custo total com mão de obra (exceto colheita), custos relacionados aos insumos como por exemplo agroquímicos, e margem de lucro. Abaixo o comparativo e comentários entre os valores informados e valores apurados via ferramenta.

\subsubsection{Custo Total anual}

Informaram inicialmente que tinham um custo de em média R\$ 750.000,00 / ano; foi apurado um custo de R\$ 919.704,00 / ano. 
Percebe-se uma forte tendência de se subestimar os custos. Notou-se que, geralmente pequenas despesas ou custos menos significantes na figura geral dos custos tendem a ser deixadas de lado, contudo, elas fazem uma diferença significativa nos números finais.

\subsubsection{Custos total com colheita}

Informaram R\$ 150.000,00 / ano e foi apurado R\$ 160.090,00 / ano. Percebe-se, em consonância com o tópico anterior, que as despesas mais significativas para o produtor são aquelas em que o mesmo possui mais acuracidade. Aqui os valores ficaram bem próximos, sendo a diferença, devido a não contabilização de alguns pequenos itens nesta modalidade de custo.

\subsubsection{Custo total com mão de obra (exceto colheita)}

Informaram R\$ 265.000,00 / ano e foi apurado R\$ 253.000,00. Mais uma vez, custos onde existe uma sensação de Importância e grandeza por parte do produtor são mais bem conhecidos e, portanto, mais bem mensurados.

\subsubsection{Custo com insumos e defensivos}

Após alguns minutos de debate, onde, aparentemente estavam calculando a dosagem aplicada por planta dos principais insumos e defensivos, versus uma multiplicação pelos preços dos mesmos, foi informado o valor de $\mathrm{R} \$$ 112.000,00. Tal valor, segundo os produtores deveria ser o valor correto da aplicação das dosagens recomendadas por planta, contudo, após análise detalhada chegou-se ao número de R\$159.143,00, ou seja, $42 \%$ a mais do que o valor estimado.

Cabe ressaltar aqui alguns pontos importantes de reflexão:

$1^{\circ}$ - Sem uma mensuração correta dos custos, os produtores não conseguem nem ao menos estabelecer a dosagem média aplicada por planta, uma vez que tais procedimentos são feitos por colaboradores, que, embora treinados, por não terem sido propriamente monitorados acabaram por aplicar dosagens incorretas dos insumos e dos defensivos, acarretando não só um gasto superior ao necessário, mas também possíveis problemas no desenvolvimento das plantas e nos níveis de produção.

Desta maneira, ao não controlar propriamente os gastos deste item de custo o prejuízo era duplo, gastos desnecessários com insumos e defensivos e perda de produtividade devido ao manejo e tratos incorretos.

$2^{\circ}$ - No cálculo, os produtores consideraram o preço à vista dos insumos e defensivos, contudo, a maior parte das compras foi feita via "barter".

Segundo Silva (2011) "barter" consiste em um contrato onde o produtor recebe uma certa quantidade de insumos ou defensivos destinados à sua produção e efetua a liquidação do compromisso de compra não com moeda, mas com a própria produção.

Com um nome diferente, plano de pagamento com prazo safra, a fornecedora de insumos aproveitou-se do momento de descapitalização do produtor para lucrar não somente na venda dos itens, mas também no financiamento do produtor. Aqui pode ser identificado mais um item que contribui e evidencia o mau gerenciamento do fluxo de caixa da atividade em que, o produtor acreditava que teria o suficiente para comprar à vista, segundo palavras do pai A.S. Contudo, no momento da compra descobrimos que não conseguiríamos pagar tudo à vista e não daria tempo de buscar um financiamento mais barato, só nos restou fazer a troca, segundo o filho A.G.S.

Se eles utilizassem de um sistema de gestão, onde teriam mais controle sobre os gastos e despesas e maior controle sobre o fluxo de caixa, poderiam ter se antecipado a falta de caixa neste período crucial do ciclo produtivo e buscado fontes de crédito mais viáveis. Somente a título de exemplo, existe hoje uma linha de crédito para custeio agrícola ou pecuário denominada Pronamp (Programa Nacional de Apoio ao Médio Produtor Rural). Pronamp é uma linha de crédito subsidiada, denominada como dinheiro marcado, que se destina a produtores rurais com faturamento bruto total anual de até R\$2.000.000,00 incluindo-se outras rendas que não do agronegócio. Para o ano safra 2018/2019 o Pronamp terá taxa máxima de 6\% a.a. BRASIL (2019).

Segundo o próprio produtor, as taxas das operações de "barter" nesta mesma empresa giram em torno de 1,5\% a 2,5\% a.m, o que corresponde na melhor das hipóteses a uma taxa anual de $19,56 \%$, ou seja, $226 \%$ maior do que a taxa cobrada em uma operação de Pronamp custeio, aqui mais uma forte evidência da diferença de uma gestão financeira eficiente.

Como exemplo, sem considerar custos de IOF, custos de cartório, seguros e demais, se um produtor tomar um crédito de $\mathrm{R} \$ 150.000,00$ com um prazo de 12 meses, assim ficariam as operações:

"Barter":

Taxa anual: 19,56\%

Valor final a ser pago após 12 meses (capital + Juros): R\$ 179.340,00

Custeio Pronamp:

Taxa anual: $6 \%$

Valor final a ser pago após 12 meses (capital + Juros): R\$ $159.000,00$

Diferença de R \$ 20.340,00 a favor do custeio.

Margem de lucro

Por fim, quando questionado sobre a margem de lucro líquido da atividade, ambos prontamente informaram que na última safra teria sido algo em torno de $25 \%$ a $30 \%$.

Após preenchimento da ferramenta e análise minuciosa dos relatórios chegamos a uma margem de 17,27\%, o que para alguns pode não ser uma diferença tão gritante, mas, este é o objetivo final da atividade, gerar riquezas. Nesta etapa qualquer diferença por mínima que seja é muito relevante.

Este número apenas veio a confirmar o que já era conhecido, os custos vinham sendo subestimados e consequentemente a margem de lucro deveria estar um pouco inflacionada. 
Assim, após a análise dos dados comparativos, percebeuse a importância de uma gestão profissional de custos pelo produtor, onde, existe espaço para ganho de eficiência e consequentemente maior ganho financeiro.

\section{Conclusão}

A maioria dos entrevistados (90,9\%) considera extremamente importante mensurar os custos de produção, porém, um percentual relativamente baixo, assumiu conhecer detalhadamente os custos de sua atividade agropecuária.

Não foi possível identificar apenas um único item responsável pela elevação dos custos e despesas dos entrevistados; pois a base de custos dos entrevistados é bem diversificada, e o universo amostral limitado.

Com a utilização e análise dos resultados da ferramenta, percebeu-se que existe uma boa margem para ganho de eficiência, especificamente dentro da cultura cafeeira. Evidenciou-se que o pequeno e médio cafeicultor carece de profissionalização na esfera administrativa e principalmente na financeira. Com apenas algumas horas semanais, como observado na aplicação prática, é possível identificar os gargalos e deficiências na ótica de finanças, e com isto, e a mais correta administração e mensuração dos custos e despesas, perpetuar a atividade com margens de lucro compatíveis com o risco dela.

\section{Referências}

BATALHA, M.O. Gestão agroindustrial: GEPAI: grupo de estudos e pesquisas agroindustriais. São Paulo: Atlas, 2009.

BORILLI, S. P.; PHILIPPSEN, R. B.; RIBEIRO, R. G.; HOFE, E. O uso da contabilidade rural como uma ferramenta gerencial: um estudo de caso dos produtos rurais no Município de Toledo - PR. Revista Ciência Empresariais da UNIPAR, v.6, n.1, 2005.

BRASIL. Ministério da Agricultura, Pecuária e Abastecimento. Plano Agrícola e Pecuário 2018/2019. 2018. Disponível em: $\quad<\quad h t t p: / / w w w . a g r i c u l t u r a . g o v \cdot b r / a s s u n t o s /$ politicaagricola/plano-agricola-e-pecuario/arquivos-pap/copy_of_ PlanoAgricolaePecurio20182019.pdf > . Acesso em: 2 abr. 2020.

BRASIL - BNDES - Banco Nacional de Desenvolvimento
Econômico e Social. Pronamp: Financiamento para custeio e investimentos dos médios produtores rurais em atividades agropecuárias. 2019. Disponível em: <https://www.bndes. gov.br/wps/portal/site/home/financiamento/produto/pronampinvestimento>. Acesso em: 2 abr. 2020

CEPEA: Participação feminina no agro é impulsionada por mulher com mais de 30 anos e maior qualificação. 2019. Disponível em: https://www.cepea.esalq.usp.br/br/releases/ cepea-participacao-feminina-no-agro-e-impulsionada-pormulher-com-mais-de-30-anos-e-maior-qualificacao.aspx. Acesso em: 3 abr. 2020.

CEPEA: Exportações do Agronegócio. 2018. Disponível em: https://www.cepea.esalq.usp.br/upload/kceditor/files/Cepea ExportAgro_1SEMESTRE_2018.pdf. Acesso em: 3 abr. 2020.

CREPALDI, S. A. Contabilidade rural: uma abordagem decisorial. São Paulo: Atlas, 2012.

CREPALDI, S. A. Contabilidade rural. São Paulo: Atlas, 2009.

DOMENICO, D. D.; MAGRO, C. B. D.; ZANIN, A.; MARTINI, R. Controle de custos na produção do gado de corte: um estudo de caso em uma propriedade rural de Santa Catarina. Revista Extensão Rural, v.22, n.3, 2015.

JOIA, L. A.; OLIVEIRA, M. F. Personalização ou Codificação? Avaliando estratégias de gestão do conhecimento. Organizações \& Sociedade, v. 14, n. 43, p. 13-36, 2007.

MORENO, J. G. Administração do tempo e seu impacto na atuação do gestor em uma empresa do setor financeiro. Fotaaleza: Universidade Federal do Ceará, 2013.

RAMOS, E. N. P.; HELAL, D. H. A prática da gestão do conhecimento em uma empresa familiar do ramo varejista em Minas Gerais (MG): Um estudo de caso. J. Inform. Syst. Technol. Manag., v.7, n.2, p.433-452, 2010.

SANTOS, G.J.; MARION, J.C.; SEGATTI, S. Administração de custos na agropecuária. São Paulo: Atlas, 2009.

SENAR - Serviço Nacional de Aprendizagem Rural. Curso técnico em agronegócio: gestão de custos. Brasília: SENAR, 2015.

SILVA, F.P. Financiamento da cadeia de grãos no Brasil: o papel das tradings e fornecedores de insumos. Campinas: UNICAMP, 2011.

SILVA, R.O. Teorias de administração. São Paulo: Pioneira Thomson Learning, 2005. 